Universidad de Lima

Facultad de Derecho

Carrera de Derecho

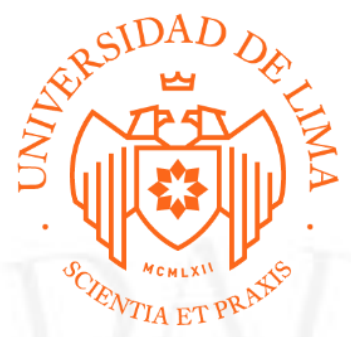

\title{
CIVIL: "ACCIÓN DE AMPARO" Y \\ ADMINISTRATIVO: "PROTECCIÓN AL CONSUMIDOR"
}

Trabajo de suficiencia profesional para optar el Título Profesional de Abogada

Mariana Cordero Morales

Código 20121645

Lima - Perú

mayo de 2019 


\section{ADMINISTRATIVO: "PROTECCIÓN AL CONSUMIDOR"}

Materia: Acción de amparo

No de Expediente: 51022-2009-0-1801-JR-CI-05

\section{RESUMEN}

Se trata de un complejo caso en el sector minero en el que se discute cuál es el plazo que corresponde aplicar para el inicio de las actividades de exploración por parte de una aurífera; y, asimismo, se busca determinar si corresponde la interposición de un proceso de amparo que involucra a las partes respecto a un laudo arbitral por árbitro único.

\section{ADMINISTRATIVO: "BARRERAS BUROCRÁTICAS"}

Materia: Protección al consumidor. Idoneidad del servicio. $\mathrm{N}^{\mathrm{o}}$ de Expediente: 51022-2009-0-1801-JR-CI-05

\section{RESUMEN}

En el presente procedimiento, se discute respecto a si una clínica, en su calidad de proveedora frente a la denunciante y consumidora, le brindó un servicio médico idóneo, toda vez que le habrían indicado de manera errónea que su pie derecho habría sufrido una fisura, debiendo ser enyesada y guardar reposo por un mes. 